06

\title{
Формирование и структура термомиграционных кремниевых каналов, легированных Ga
}

\author{
(ㄱ А.А. Ломов, ${ }^{1}$ Б.М. Середин, ${ }^{2}$ С.Ю. Мартюшов, ${ }^{3}$ А.Н. Заиченко, ${ }^{2}$ И.Л. Шульпина ${ }^{4}$ \\ ${ }^{1}$ Физико-технологический институт им. К.А. Валиева РАН, \\ 117218 Москва, Россия \\ ${ }^{2}$ Южно-Российский государственный политехнический университет (НПИ) им. М.И. Платова, \\ 346428 Новочеркасск, Россия \\ ${ }^{3}$ Технологический институт сверхтвердых и новых углеродных материалов, \\ 108840 Троицк, Россия \\ ${ }^{4}$ Физико-технический институт им. А.Ф. Иофффе РАН, \\ 194021Санкт-Петербург, Россия \\ e-mail: lomov@ftian.ru
}

Поступило в Редакцию 5 июля 2020 г.

В окончательной редакции 26 августа 2020 г.

Принято к публикации 8 сентября 2020 г.

\begin{abstract}
Методом термомиграции локальных галлиевых зон в пластинах c-Si(111) при температуре $1450 \mathrm{~K}$ созданы сквозные вертикальные $p$-каналы $\mathrm{Si}(\mathrm{Ga})$. Для достижения этой цели предложена и реализована методика формирования локальных зон, состоящая в заполнении высокодисперсным порошком Ga вытравленных в

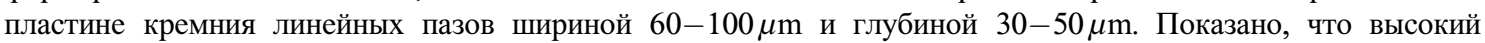
выход годных зон происходит при размере зерен порошка $5 \mu \mathrm{m}$ и температуре $\sim 284 \mathrm{~K}$. Полученные термомиграционные $p$-каналы $\mathrm{Si}(\mathrm{Ga})$ исследованы рентгеновскими методами двухкристальных кривых дифракционного отражения и проекционной топографии. Характеризация структурного совершенства галлиевых $p$-каналов выполнена на основе их сравнения с особенностями строения термомиграционных каналов $\mathrm{Si}(\mathrm{Al})$, полученных вблизи „ретроградной“ температуры $1380 \mathrm{~K}$. Показано, что типичным видом структурных дефектов на границах обоих термомиграционных каналов являются дислокационные полупетли, закрепленные своими концами на их границах. Определены величины деформации $(2-5) \cdot 10^{-5}$ и изгиба $\left(15^{\prime \prime}-30^{\prime \prime}\right)$ кристаллических плоскостей вблизи границы канал-матрица пластины исследуемых образцов. Концентрация внедренных атомов алюминия и галлия в кристаллическую решетку кремниевых каналов образцов в модели Вегарда составила $C_{\mathrm{Al}} \sim 10^{19} \mathrm{~cm}^{-3}$ и $C_{\mathrm{Ga}} \sim 1.9 \cdot 10^{19} \mathrm{~cm}^{-3}$ соответственно.
\end{abstract}

Ключевые слова: термомиграция, локальное легирование, каналы, кремний, галлий, алюминий, рентгеновская топография, высокоразрешающая дифрактометрия.

DOI: 10.21883/JTF.2021.03.50525.220-20

\section{Введение}

Вертикальные сквозные $р$-каналы и их массивы в монокристаллических полупроводниковых пластинах представляют особый класс востребованных материалов для различных применений: силовых приборов на токи до 100 А, высоковольтных выпрямителей, ограничителей переменного тока, фотоэлектрических преобразователей, МЭМС, электрических изоляторов, биосенсоров [13]. Для создания сквозных р-каналов применяется метод термомиграции (ThM) жидких зон, известный также как метод зонной перекристаллизации градиентом температуры [4,5]. Метод ТhM обладает по сравнению с методом диффузии рядом неоспоримых преимуществ. К ним нужно отнести постоянную концентрацию легирующей примеси по глубине канала, дециминутную длительность процесса ThM, резкость $p-n$-перехода на границе канала [6-9]. Сформированные ТhМ-каналы являются монокристаллическими с малым количеством структурных дефектов [10]. Изменением температуры, ее градиента, окружающей средой и временем про- цесса ThM возможно управлять геометрией, структурным совершенством и величиной проводимости $p$-каналов [11-14].

Модификация свойств термомиграционных $p$-каналов в кремнии связана с возможностью варьирования в них величиной концентрации акцепторов за счет выбора материала-растворителя. При этом должна сохраняться высокая скорость ТhM в качестве основной уникальной особенности процесса. Растворитель должен удовлетворять ряду требований: принадлежать к третьей группы периодической системы; растворять кремний при температурах, меньших, чем его температура плавления; смачивать кремний; не испаряться в условиях проведения процесса; минимально искажать параметры кристаллической решетки кремния. К третьей группе элементов относятся неметалл (В) и металлы (Al, $\mathrm{Ga}, \mathrm{In}, \mathrm{Ta})$. Однако бор, входящий в третью группу элементов, не отвечает вышеуказанным требованиям, поэтому не используется.

Анализ диаграммы фазового состояния $\mathrm{Tl}-\mathrm{Si}$ показывает, что таллий относится к таким легирующим 
примесям, введение которых трудно реализуемо. Кроме этого, таллий летуч, токсичен, не смачивает кремний вплоть до температуры плавления последнего. Поэтому этот металл для термомиграции с использованием кремниевых подложек не используют. Применение индия в процессе ThM возможно. Но его использование затруднено по ряду причин: необходимость проведения процесса при высоких температурах $(\sim 1600 \mathrm{~K})$, при которых кремний становится пластичным; значительное отличие в величинах ковалентных радиусов индия и кремния; высокое давления паров индия.

Наиболее технологичным металлом при формировании термомиграцией $p$-каналов в кремнии является алюминий $[5,11-16]$. Жидкий алюминий имеет низкое давление паров и хорошо смачивает кремний при температурах $1300-1500 \mathrm{~K}$. Алюминий, находясь в позиции замещения, незначительно искажает кристаллическую решетку кремния из-за близости их ковалентных радиусов. В то же время растворимость алюминия в кремнии (с образованием твердого раствора) имеет ярко выраженный ретроградный характер с пределом $2 \cdot 10^{19} \mathrm{~cm}^{-3}$ при температуре $\sim 1530 \mathrm{~K}[5,12,17]$.

Применение $\mathrm{Ga}$ для формирования $p$-каналов в кремнии методом ТhM могло бы увеличить концентрацию акцепторов в $\sim 2$ раза по сравнению с лигатурой на основе алюминия. Свойства этого металла позволяют быть в качестве растворителя для проведения процесса термомиграции в кремнии. Поскольку ковалентный радиус галлия превосходит радиус кремния всего на $\sim 0.01 \mathrm{~nm}$, то можно ожидать достаточное совершенство формируемых структур. К недостаткам галлия надо отнести плохое смачивание и растворимость кремния при низких температурах. Поэтому температурный диапазон для практического применения процесса ТМ в кремнии на основе лигатуры галлия узок и равен $1400-1500 \mathrm{~K}$. Однако доказательств формирования галлиевых каналов и достижения в них высоких концентраций до настоящей работы не представлено.

В [18] было показано, что в процессе ТhM лигатуры галлия при температуре $1600 \mathrm{~K}$ концентрация акцепторов в слоях кремния может быть увеличена до $\sim 5 \cdot 10^{19} \mathrm{~cm}^{-3}$. Это особенно важно для уменьшения потерь напряжения при прямом протекании тока через $p-n$-переход и повышения эффективности прибора. Особенность галлия в том, что он до температур $1200-1300 \mathrm{~K}$ слабее растворяет кремний (до 5 wt.\%)[19] по сравнению с алюминием (до 40 wt.\%) [20]). Поэтому для начала процесса ThM необходимо повысить за счет температуры концентрацию кремния в лигатуре галлия и увеличить глубину залегания расплава. Несмотря как на фундаментальный, так и на практический интерес к галлиевым ТhМ-каналам в кремнии, к настоящему времени отсутствуют сообщения о возможности их получения кроме предпринятой попытки в [21].

Получение $p$-канала осуществляется за счет локальной перекристаллизации монокристаллической пластины при направленном движении с постоянной скоро- стью зоны расплава от фронтальной к более нагретой тыльной стороне пластины. Стабильное воспроизведение требуемых параметров ТhМ-каналов тесно связано с проблемой [5] формирования локальных жидких зон в объеме полупроводниковой пластины, что в ряде случаев не является тривиальной задачей. Для ее решения необходимо обеспечить локальное избирательное смачивание поверхности пластины жидкой лигатурой [15] и разработку вакуумного специализированного оборудования - устройства формирования локальных жидких зон [16].

Высокоразрешающая рентгеновская дифрактометрия и рентгеновская топография являются мощными инструментами для исследования реальной структуры кристаллов. В последние десятилетия многочисленное применение этих методик в основном ограничено характеризацией дефектов структуры в объеме полупроводниковых пластин, определением деформации, состава и дислокаций в эпитаксиальных слоях и многослойных гетероструктурах [22]. В то же время эти методики наиболее удобны для диагностики структурных особенностей ThМ-каналов. Однако работ, посвященных исследованию особенностей структуры и дефектам даже в каналах $\mathrm{Si}(\mathrm{Al})$, за исключением $[10,12,15,23,24]$, практически нет. Отметим, что структурная модель ТhМ-каналов необычна и достаточно сложна, экспериментальные результаты не допускают простой интерпретации [10,25]. Требуется проведение комплексных исследований с привлечением модельных образцов.

Целью настоящей работы является разработка методики локального легирования кремния галлием для формирования массива плоских $p$-каналов в монокристаллической пластине кремния и исследование особенностей их структуры в сравнении с ТhМ-каналами в кремнии, полученными на основе лигатуры алюминия.

\section{1. Формирование локальных галлиевых зон}

Для получения легированных галлием кремниевых каналов (рис. 1) нами предлагается использовать его высокодисперсный порошок. Порошок галлия располагался в пазах глубиной $h$ и шириной $l_{\mathrm{F}}$, предварительно вытравленных на фронтальной поверхности пластины в местах будущих каналов. Пазы создавались кислотным травлением поверхности кремния благодаря вскрытым окнам в защитном покрытии из фоторезиста и диоксида кремния толщиной $h_{0} l$. Для изотропного травления кремния использовалась смесь кислот $\mathrm{HF}: \mathrm{HNO}_{3}: \mathrm{CH}_{3} \mathrm{COOH}(2: 9: 4)$, что позволило достичь соотношения $l_{\mathrm{F}} \geq h$. На следующем этапе (рис. $\left.1, b\right)$ пластина (без фоторезиста) протягивалась со скоростью $v$ под тиглем 2 со щелью шириной $L_{T}\left(L_{T}>l_{\mathrm{F}}\right)$ с находящимся в нем при температуре $T_{S}$ порошком кристаллического галлия 3. Порошок 4 после протяжки под тиглем заполнял вытравленные пазы. Необходимо 

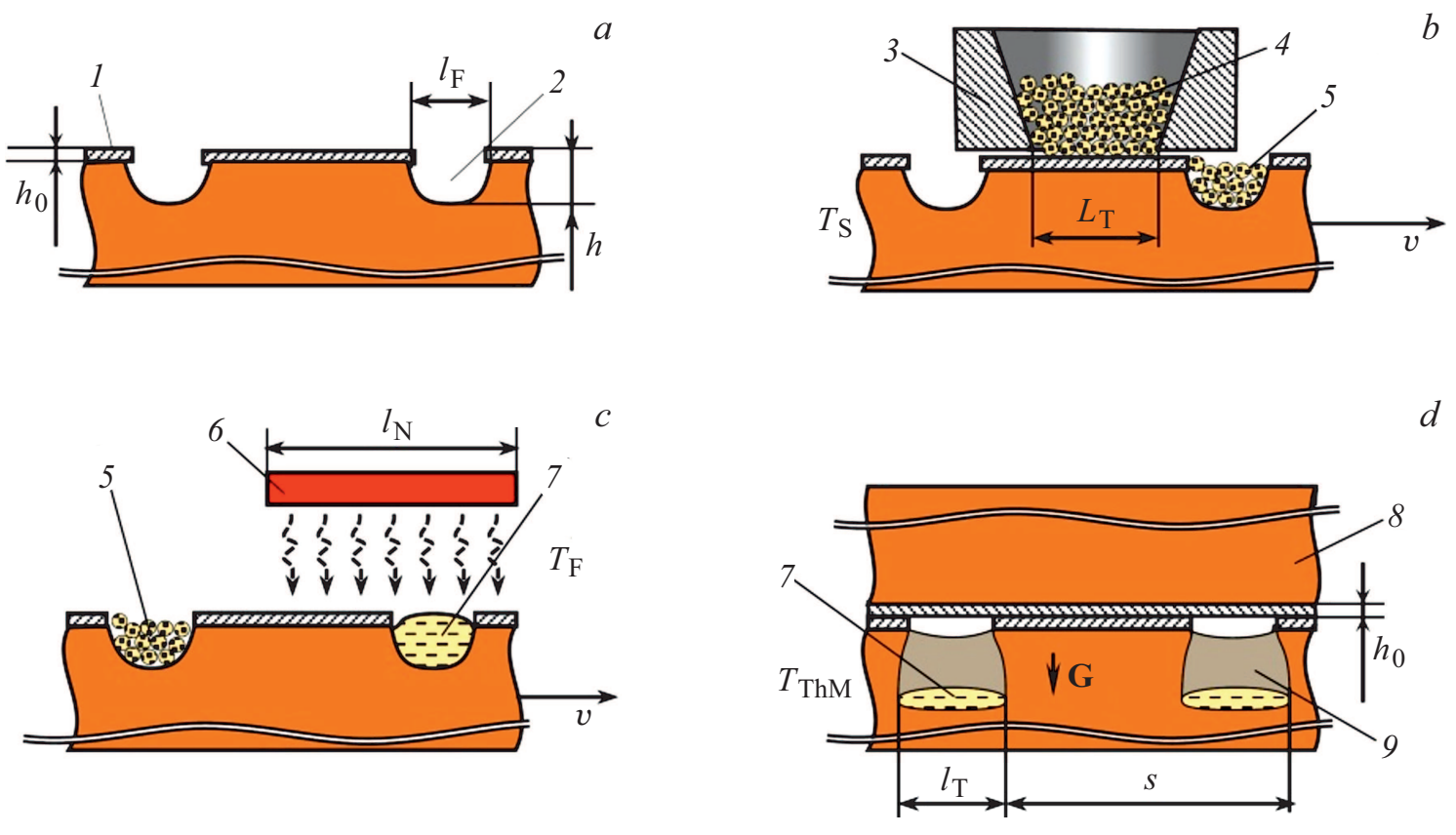

Рис. 1. Последовательность операции формирования локальных зон: 1 - слой маскирующего покрытия на пластине $\mathrm{Si}$; 2 - паз; 3 - тигель; 4 - галлиевый порошок; 5 - порошок в пазах; 6 - нагреватель; 7 - жидкая зона; 8 - окисленная пластина-спутник; 9 - термомиграционный канал $\mathrm{Si}(\mathrm{Ga}), G$ - градиент температуры.

отметить, что размер зерен (диаметр шариков $d$ ) порошка должен быть меньше $l_{\mathrm{F}}$ и $h$. После перемещения пластины кремния с осажденным порошком галлия 5 в нагревательный узел 6 (рис. $1, c$ ) происходило его расплавление при температуре $\left(T_{\mathrm{F}}\right)$ и заполнение пазов расплавом 7. Плавление предназначалось для „закрепления“ галлия в пазах на фронтальной поверхности пластины кремния и облегчения старта ThM-процесса.

Отработка технологии формирования галлиевых зон проводилась на пластинах $\mathrm{Si}(111) n$-типа с удельным сопротивлением $(\rho) 4.5 \Omega \cdot \mathrm{cm}$. На поверхности пластин создавался слой термического окисла толщиной $h_{0}=1 \mu \mathrm{m}$. В защитном слое формировали параллельные пазы (рис. $1, d)$ с топологическим размером $s=3 \mathrm{~mm}$, шириной $l_{\mathrm{F}}=60-100 \mu \mathrm{m}$ и глубиной $h=30-50 \mu \mathrm{m}$. В качестве порошка использовался галлий $\mathrm{Ga} 5 \mathrm{~N}$ в виде шариков диаметром $d=5-50 \mu \mathrm{m}$. Шаг варьирования технологических параметров $l_{\mathrm{F}}, h, d$ составлял $5 \mu \mathrm{m}$. Для получения порошка галлия требуемого диаметра он загружался в экструдер, где доводился до жидкого состояния. В дальнейшем расплав галлия впрыскивали на водоохлаждаемую изложницу. Диаметр шариков галлия определялся подбором сечения экструдера, его температуры и давления впрыска расплава. Заполнение пазов порошком галлия и его расплавление проводилось в вакууме при $T_{S}=280-300 \mathrm{~K}$ и $T_{\mathrm{F}}=350-450 \mathrm{~K}$ соответственно. В дальнейшем пластину переносили в камеру процесса ThM (рис. 1,d). С целью предотвращения испарения галлия на начальном этапе движения расплава сквозь пластину фронтальная поверхность пластины с

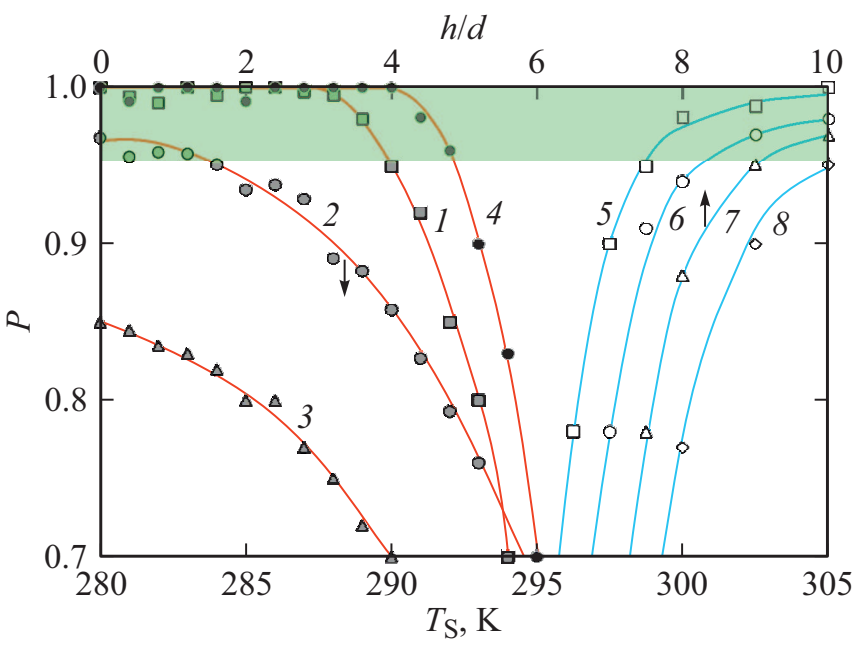

Рис. 2. Температурные $(1-4)$ и аспектные $h / d(5-8)$ зависимости выхода $P$-годных галлиевых зон соответственно: $1-3$ - для $h / d=10 ; 6 ; 4$ и $v=0.3 \mathrm{~m} / \mathrm{s} ; 4-h / d=10$; $v=0.2 \mathrm{~m} / \mathrm{s} ; 5-8$ - для $v=0.2 ; 0.3 ; 0.34 ; 0.38 \mathrm{~m} / \mathrm{s}$ при $T_{S}=287 \mathrm{~K}$.

пазами закрывалась отдельными полосками кремния или дополнительной пластиной кремния 8 .

Экспериментальные условия получения галлиевых зон на пластине кремния показаны на рис. 2.

Из представленных на рис. 2 зависимостей качества $P$ локальных галлиевых зон видно, что при заданной топологии каналов заполнение галлием пазов без разрывов 
$(P \geq 0.95)$ критично к температуре формирования $T_{S}$, скорости протягивания $v$, соотношению $h / d$. Выход годных локальных зон в пределах опытной партии обрабатываемых пластин оценивался по величине $P=N_{i} / N$, где $N_{i}$ и $N$ - количество зон, имеющих полное заполнение, и общее количество зон на пластине соответственно. Критерием полного заполнения углубления порошком являлось его заполнение по ширине и глубине более чем на 90\%. Контроль качества заполнения каналов проводили с помощью оптической микроскопии.

Анализ данных (рис. 2, кривые 1-3) о влиянии температуры формирования $T_{S}$ на $P$ показывает, что для обеспечения высокого выхода годных локальных зон $P \leq 0.95$ (область окрашена) величина $T_{S}$ не должна превышать $284 \mathrm{~K}$. Отметим, что приближение температуры заполнения каналов шариками к температуре плавления галлия $(302 \mathrm{~K})$ приводит к неработоспособности методики.

Выход $p$-годных галлиевых зон растет с увеличением аспектного отношения $h / d$. Уменьшение $h / d$ до 4 резко снижает эффективность методики (кривая 3). Для стабильной термомиграции зон в кремнии обычно выбирают $h$ в диапазоне $30-50 \mu \mathrm{m}[15,16]$. В этих условиях необходимо использовать порошок диаметром менее $5 \mu \mathrm{m}$, который получить в экструдере технологически сложнее. В этой связи приемлемыми с учетом температуры порошка являются значения $h / d$ больше 6 .

Скорость $v$ протягивания тигля над пластиной также оказывает заметное влияние на величину $P$. Сравнивая зависимости 5-8, видно, что уменьшение скорости протягивания пластины увеличивает эффективность методики получения качественных галлиевых зон (кривая 5). Этот вывод подтверждается ходом кривой $4(v=0.2 \mathrm{~m} / \mathrm{s})$, которая смещена правее кривой 1 $(v=0.3 \mathrm{~m} / \mathrm{s})$.

\section{2. Образцы и методы исследования}

Образцы легированных алюминием и галлием методом ТhМ-каналов в матрице (рис. $1, d, 9$ ) пластины кремния $\operatorname{Si}(111)$ (толщиной $t=0.45 \mathrm{~mm}, n$-типа, с удельным сопротивлением $4.5 \Omega \mathrm{cm}$ ) были получены в вакууме. Каналы $\mathrm{Si}(\mathrm{Al})$ перекристаллизовались при температуре $T_{\mathrm{ThM}}=1380 \mathrm{~K}$ и градиенте $G=50-100 \mathrm{~K} / \mathrm{cm}$, реализованным посредством графитового нагревателя, размещенного в водоохлаждаемой камере [15], а каналы $\mathrm{Si}(\mathrm{Ga})$ - формировались на основе предлагаемой выше методики при $h / d=4$ и $8, T_{\mathrm{ThM}}=1400-1500 \mathrm{~K}$ и $G=50-100 \mathrm{~K} / \mathrm{cm}$ в течение $60 \mathrm{~min}$ (в условиях [15]).

Анализ структурного совершенства ThM каналов $\mathrm{Si}(\mathrm{Ga})$ был выполнен рентгеновскими методами проекционной топографии и двухкристальных кривых дифракционного отражения (КДО). Рентгенотопографические исследования были проведены методом Ланга на установке XRT100CCM (Rigaku Co.) с использованием излучения от 12-kW вращающегося серебряного анода.
Величина линейного коэффициента фотоэлектрического поглощения в кремнии $\mu=8 \mathrm{~cm}^{-1}$. Для регистрации дифракционного изображения использовалась рентгеновская фотопленка.

Кривые дифракционного 111 и 333 отражения в геометрии Брэгга записывались на трехкристальном рентгеновском спектрометре ТРС (СКБ ИКАН РАН) при параллельном бездисперсионном расположении кристаллов с плоским кристаллом-монохроматором $\mathrm{Si}(111)$. Источником излучения служила рентгеновская трубка с медным анодом и видимым размером фокуса в плоскости (горизонтальной) дифракции $0.05 \mathrm{~mm}$ и $10 \mathrm{~mm}$ перпендикулярно к ней. Размеры выходных щелей коллиматора были равны 0.06 и $2 \mathrm{~mm}$ соответственно. При записи КДО от образца с каналами возникает проблема его адекватной юстировки. В случае рассеяния от кристаллической пластины с однородным планарным эпитаксиальным слоем площади засветки слоя и подложки равны. При наличии сквозного вертикального канала в матрице образца вклады от него и от матрицы пластины в интенсивность отраженного рентгеновского пучка будут пропорциональны площадям их засветки. Малая ширина канала предопределяла узость первичного пучка и дополнительную настройку образца. При установке образца с ThM-каналом в отражающее положение он проходил предварительную и окончательную юстировку. На первом этапе азимутальным вращением вокруг нормали к поверхности образца достигалось расположение канала параллельно вертикальной оси гониометра. После обнаружения на КДО двух пиков (засветка области вблизи канала) образец дополнительно юстировался по максимальному провалу между ними.

\section{3. Результаты и обсуждение}

\section{1. Вертикальные $\mathrm{Si}(\mathrm{Al})-$-каналы}

На рис. 3 представлен фрагмент проекционной топограммы образца кремния с двумя $p$-каналами $\mathrm{Si}(\mathrm{Al})$, полученными методом ТhM при $T=1380 \mathrm{~K}$. Каналы с границами хорошо видны в виде параллельных полос переменного контраста.

Более светлая часть $(p K)$ полосы шириной $0.08 \mathrm{~mm}$ соответствует центральной части канала $\mathrm{Si}(\mathrm{Al})$. Широкие черные полосы $p 2$ и p3 шириной $0.11-0.12 \mathrm{~mm}$, окаймляющие канал по обе его стороны, соответствуют переходным областям вблизи границ канала. Эти области характеризуются значительными искажениями кристаллической решетки из-за релаксации напряжений на вертикальной стенке канала. Несмотря на это центральные части каналов на основе лигатуры алюминия являются совершенными монокристаллическими областями с низкой плотностью дислокаций. Центральная часть канала светлая, что говорит о динамическом характере рассеяния в объеме канала. В поверхностных слоях образца вдоль обеих границ каналов лежат дислокационные полупетли (HL). Своими концами они 


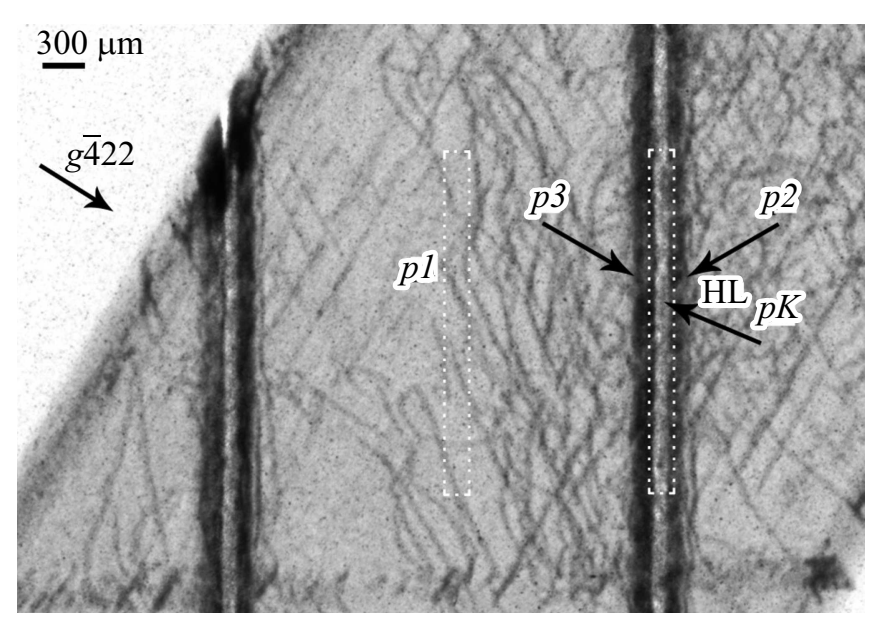

Рис. 3. Фрагмент рентгеновской проекционной топограммы пластины $\mathrm{Si}(111)$ с массивом каналов $\mathrm{Si}(\mathrm{Al}) . \mathrm{Ag} K_{\alpha}$-излучение, $\mu \cdot t=0.36$. HL - дислокационные полупетли; $p K-$ канал, $p 1$ - область между каналами, $p 2$ и $p 3$ - границы канала (точками выделена область засветки пластины при записи кривых дифракционного отражения, рис. 4).

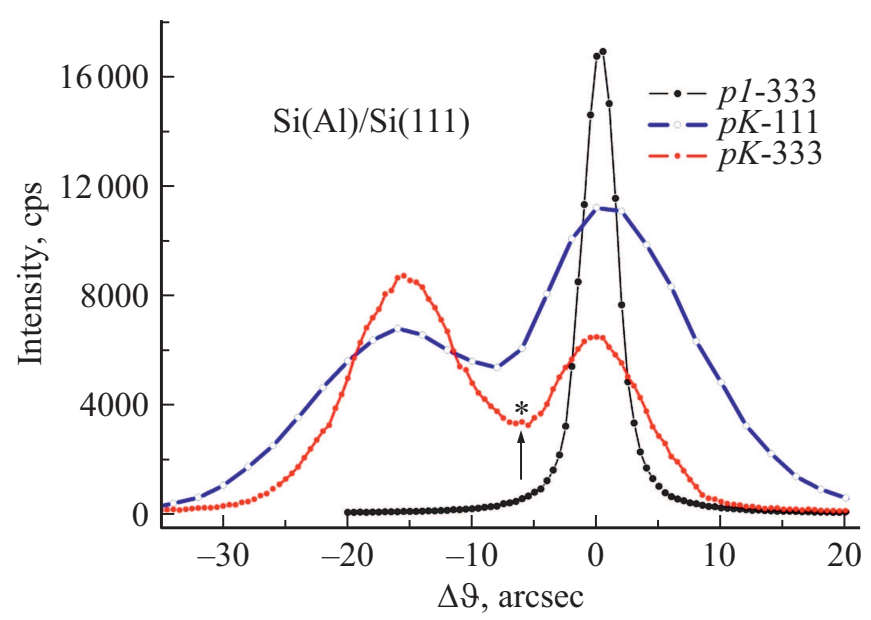

Рис. 4. Двухкристальные кривые дифракционного отражения от различных участков пластины $\mathrm{Si}(111)$ с $\mathrm{ThM}$ р-каналом $\mathrm{Si}(\mathrm{Al})$ шириной $0.1-0.12 \mathrm{~mm}$ : вдали (p1-333) и в области $p$ канала $(p K-111, p K-333) ;{ }^{8}$ - отражение от центральной части $\mathrm{Si}(\mathrm{Al})$-канала. $\mathrm{Cu} K_{\alpha 1}$-излучение, 111 и 333 отражения.

закреплены на границах каналов. Их разбег от границ каналов составляет 2-3 ширины канала и зависит от температуры ThM-процесса. Дополнительно наблюдаются не связанные с каналами дислокации (сравни левый и правый каналы). Релаксация напряжений вблизи поверхности образца на границе каналов происходит за счет изгиба кристаллических плоскостей, а не за счет диффузии алюминия на границе канал-матрица пластины [23]. Проведенные ранее рентгенодифракционные исследования ТhM-слоев $\mathrm{Si}(\mathrm{Al}) / \mathrm{Si}\left(C_{\mathrm{Al}} \sim 10^{19} \mathrm{~cm}^{-3}\right.$, $T=1350 \mathrm{~K})$ с толщиной до $60 \mu \mathrm{m}$ показывают, что появление дислокаций несоответствия на границе кана- лов маловероятны [19]. В матрице образца присутствуют единичные дислокации и полосы скольжения вдоль „011“, образующиеся из-за температурных напряжений и уменьшении величины модуля Юнга при высоких температурах.

На рис. 4 показаны двухкристальные кривые дифракционного 111 и 333 отражений в геометрии Брэгга от образца с $p$-каналами $\mathrm{Si}(\mathrm{Al}) / \mathrm{Si}$, записанные от участков поверхности в точках $p 1$ и $p K$ (рис. 3 ) в зависимости от $\Delta \vartheta=\vartheta-\vartheta_{B}\left(\vartheta_{B}-\right.$ угол Брэгга $)$.

Видно, что в зависимости от места засветки (рис. 3) и порядка отражения рентгеновского пучка на кривых дифракционного отражения наблюдаются один пик (кривая $p 1)$, два пика (кривая $p K-111)$ или два пика и максимум (кривая $p K-333)$. Пик на дифракционной кривой $p 1$ 333 (участок поверхности между каналами) имеет полуширину $3.5 \operatorname{arcsec}$, что близко к значению $2.63 \operatorname{arcsec}$ для совершенного кристалла кремния согласно динамической теории рассеяния [22]. Дополнительное уширение $\sim 0.8 \operatorname{arcsec}$ связано с незначительной мозаичностью, изгибом образца после приготовления и аппаратными искажениями. На кривых КДО от участка поверхности с каналом $\mathrm{Si}(\mathrm{Al})$ в общем случае наблюдаются два более широких пика. Угловое расстояние $\Delta \vartheta$ между этими пиками на КДО обусловлено как деформацией $\Delta d / d$, так и разориентацией $\Psi$ участков поверхности: $\Delta \vartheta=\Delta \vartheta(\Psi)+\Delta \vartheta(\Delta d / d)$. На представленных кривых КДО от 111 и 333 отражений (рис. 4) видно, что величина $\Delta \vartheta$ не меняется и равна 16 arcsec. Это показывает, что пики обусловлены развернутыми относительно друг друга участками матрицы вблизи границ канала $\mathrm{Si}(\mathrm{Al})$, а не с изменением межплоскостного расстояния кристаллических плоскостей (111) в канале. Отметим, что полуширины этих пиков зависят как от порядка отражения, так и от ширины засветки поверхности образца и равны 18 и $8 \operatorname{arcsec}$ для 111 и 333 отражений соответственно. Переход на 333 отражение позволил наблюдать на КДО появление при $\Delta \vartheta=4.5 \mathrm{deg}$ слабого максимума (звездочка на рис. 4). Выполненные ранее авторами исследования методом ВИМС элементного состава в канале $\mathrm{Si}(\mathrm{Al})$ показали, что концентрация алюминия вблизи поверхности равна $0.85 \cdot 10^{19} \mathrm{~cm}^{-3}[25]$. Результаты топографических исследований, симметричная архитектура канала и наличие в нем атомов алюминия позволяют предположить, что этот максимум связан с изменением межплоскостного расстояния в канале. Величина концентрации алюминия, восстановленная с учетом тетрагональных искажений в модели внедрения атомов в узлы кристаллической решетки кремния $C_{\mathrm{Al}}=K(\Delta d / d)\left(1 /\left\langle\beta_{\mathrm{Al}}\right\rangle\right)$ равна $\sim 10^{19} \mathrm{~cm}^{-3}$, где: $\beta_{\mathrm{Al}}=\left[1 /\left(3 C_{\mathrm{Si}}\right)\right] \cdot\left[\left(r_{\mathrm{Al}} / r_{\mathrm{Si}}\right)^{3}-1\right]$, a $C_{\mathrm{Si}}=5 \cdot 10^{19} \mathrm{~cm}^{-3}-$ концентрация атомов кремния, $K \approx 0.695$ для $\mathrm{Si}(111)$ и $r_{\mathrm{Si}}=0.117 \mathrm{~nm}, r_{\mathrm{Al}}=0.126 \mathrm{~nm}$ ковалентные радиусы атомов кремния и алюминия соответственно [26].

Наблюдаемые на основе анализа КДО особенности искажения кристаллической решетки вблизи канала и найденная концентрация алюминия в нем характеризуют 
$a$
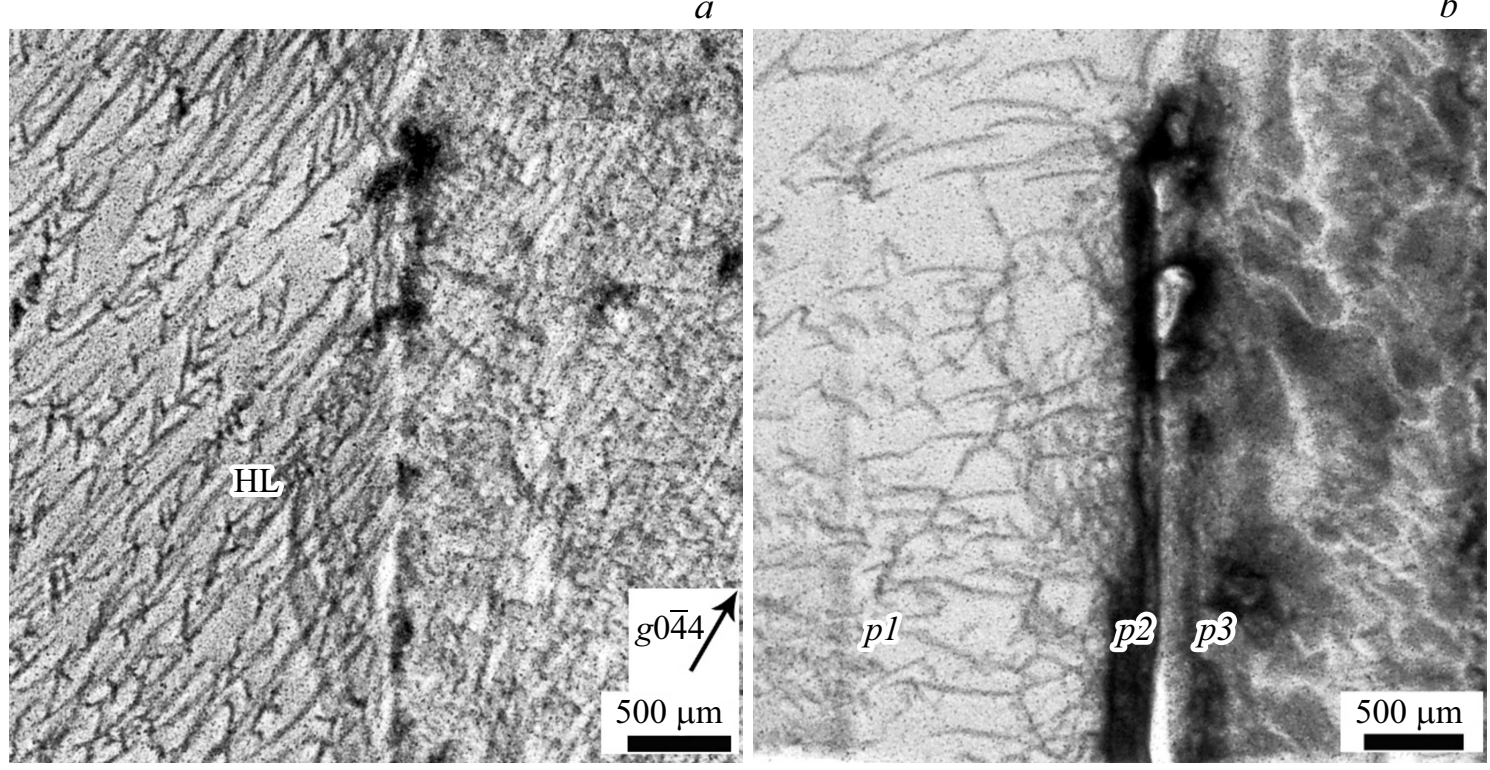

Рис. 5. Фрагменты рентгеновской проекционной топограммы пластины $\mathrm{Si}(111)$ с первыми ТhМ-каналами на основе лигатуры галлия $\mathrm{Si}(\mathrm{Ga})$, полученные при $h / d=8(a)$ и $h / d=4(b) ; \operatorname{Ag} K_{\alpha 1} 1$-источник, $\mu \cdot t=0.36$. HL - дислокационные полупетли;. $p 1-p 3$ - участки записи кривых дифракционного отражения.

канал только в приповерхностном слое пластины толщиной $10-15 \mu \mathrm{m}$, определяемой глубиной экстинкции [22]. Поэтому хорошее совпадение величины концентрации $\mathrm{CAl}$ в канале $\mathrm{Si}(\mathrm{Al})$ с данными ВИМС и с восстановленными по КДО от слоев $\mathrm{Si}(\mathrm{Al})$ [19] не закрывает вопрос о концентрации алюминия в глубине канала, искажениях кристаллической решетки на его границах с матрицей пластины. Для изучения возможности определения структурных искажений по глубине канала должны быть проведены дифракционные измерения в геометрии Лауэ. Полученные результаты о величине деформации в приповерхностных слоях канала $\mathrm{Si}(\mathrm{Al})$ были подтверждены результатами исследований, выполненных методом трехкристальной рентгеновской дифрактометрии, и будут представлены в дальнейшем.

\section{2. Вертикальные $\mathrm{Si}(\mathrm{Ga})$-каналы}

На рис. 5 представлены фрагменты рентгеновской проекционной топограммы от пластины кремния с изображением первых термомиграционных каналов на основе лигатуры галлия. Анализ изображений каналов показывает, что они прошли различные стадии процесса ThM (выхода зоны расплава на тыльную сторону пластины). По-видимому, процесс ThM на различных участках образца проходил с различной скоростью и динамикой.

Канал $\mathrm{Si}(\mathrm{Ga})$ (рис. 5,a) окружен дислокационными полупетлями HL (аналогично полупетлям вблизи канала $\mathrm{Si}(\mathrm{Al})$ на рис. 3), сосредоточенными вдоль границы канала. Этот канал формировался с аспектным соотношением $h / d=8$. Отметим, что процесс ТhМ длился менее часа и, видимо, начался с большой задержкой.
В силу этого, формирование канала закончилось на ранней стадии - он не достиг тыльной поверхности пластины.

На фрагменте топограммы (рис. 5, $b$ ) видно изображение канала $\mathrm{Si}(\mathrm{Ga})$, который получен из локальной зоны галлия, сформированной при аспектном соотношении $h / d=4$. Процесс ТhM при данном условии проходил интенсивно. Отметим, что тонкие зоны имеют меньшие скорости термомиграции и склонны к разрывам на фрагменты [5]. Поэтому отдельные части канала значительно углублены в пластину, а другие - вышли на тыльную поверхность. В результате кроме характерных дислокационных полупетель вдоль границы канала наблюдаются обширные дефектные области. Хорошо виден участок „подтрава“ матрицы (белая полоса). Исходя из полученных данных, следует, что отношение $h / d$ необходимо выбирать максимально возможным, чтобы исключить фрагментацию жидкой зоны на ее старте.

Для изучения структурного совершенства образца вблизи канала $\mathrm{Si}(\mathrm{Ga})$ (рис. 5, b), вышедшего на тыльную поверхность пластины, были записаны кривые дифракционного отражения от различных участков $p 1-p 3$ (рис. 6). Видно, что вид КДО в зависимости от участка засветки пластины вблизи канала меняется по аналогии с кривыми отражения вблизи канала $\mathrm{Si}(\mathrm{Al})$ (рис. 4).

Вдали от канала на кривой наблюдается один узкий пик, а вблизи канала его ширина увеличивается и появляются дополнительные максимумы при углах, меньших угла Брэгга. Максимумы при угле $\Delta \vartheta=-23,-33 \operatorname{arcsec}$ появляются из-за изгиба кристаллических плоскостей вблизи канала. Однако размеры приграничной области не резкие (рис. $5, b)$ и на хвосте основного максимума 


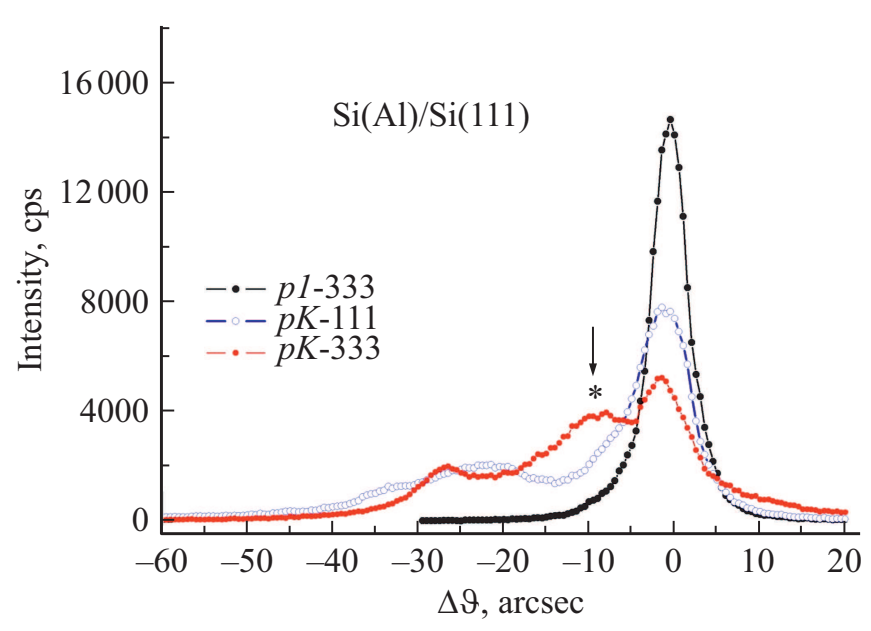

Рис. 6. Двухкристальные кривые дифракционного 333 отражения от различных участков $p 1-p 3$ (рис. $5, b$ ) тыльной поверхности пластины $\mathrm{Si}(111)$ с ТhМ-каналом $\mathrm{Si}(\mathrm{Ga}): p 1-$ вдали от канала, $p 2-$ на границе с каналом, $p 3-$ в области канала; * - отражение от канала. $\mathrm{Cu} K_{\alpha 1}$-излучение.

наблюдается слабый горб при угле $\Delta \vartheta=-9 \operatorname{arcsec}$. Этот горб превращается в максимум при записи КДО от участка $p 3$. Угловое положение максимума относительно пика от матрицы пластины соответствует величине деформации $\Delta d / d=5 \cdot 10^{-5}$ и связано с вхождением галлия в решетку кремния. На основании данных [27] зависимости концентрации галлия в ТhM-слоях кремния от температуры можно оценить концентрацию галлия в канале как $\sim 1.9 \cdot 10^{19} \mathrm{~cm}^{-3}$. Надо отметить, что эта величина заметно уступает концентрациям галлия в тонких слоях $\mathrm{Si}(\mathrm{Ga})$, которые можно получить жидкофазной эпитаксией [28] и диффузией [29]. В [27] показано, что процесс ТhM при $1600 \mathrm{~K}$ позволяет увеличить концентрацию галлия в кремнии в $2-3$ раза. Однако повышение $T_{\mathrm{ThM}}$ приводит к образованию большого количества структурных дефектов в объеме пластины кремния.

\section{Заключение и выводы}

Предложен новый подход к процессу получения стабильных локальных галлиевых зон на поверхности кремниевых пластин. Формирование галлиевых зон основано на создании углублений в защитных слоях кремниевой пластины, заполненных микрошариками Ga. Установлены оптимальная температура $284 \mathrm{~K}$ для формирования зон, диапазон аспектного соотношения глубины паза к диаметру галлиевых шариков $h / d=6-10$ и скорость движения тигля при формировании зоны $0.2-0.3 \mathrm{~m} / \mathrm{s}$.

Методом термомиграции галлия при температуре $1450 \mathrm{~K}$ в пластине $\mathrm{Si}(111) n$-типа получен массив плоских $p$-каналов. Исследования реальной структуры полученных каналов проведены рентгеновскими методами двухкристальных кривых дифракционного отражения в геометрии Брэгга и проекционной топографии (по ме- тоду Ланга). Показано, что на границах каналов типичным видом структурных дефектов являются дислокационные полупетли. Определены величина деформации $\left(\sim 5 \cdot 10^{-5}\right)$ в канале, изгиб $(20-30 \operatorname{arcsec})$ кристаллических плоскостей на границе канала вблизи его выхода на поверхность пластины и оценена концентрация галлия равная $C_{\mathrm{Ga}} \sim 1.9 \cdot 10^{19} \mathrm{~cm}^{-3}$.

Показано, что механизм формирования $p$-каналов на основе галлия и алюминия аналогичен. Закономерность этого состоит в равенстве ковалентных радиусов галлия и алюминия и квазиравновесного характером межфазных процессов растворения и кристаллизации при термомиграции. Показано, что при прочих равных условиях концентрация акцепторной примеси в $p$-канале галлия выше, чем в случае алюминия.

\section{3. Финансирование работы}

Работа выполнена в рамках Государственного задания ФТИАН им. К.А. Валиева РАН по теме № 0066-20190004 и частично поддержана РФФИ, грант № 19-0700306. Работа И.Л. Шульпиной выполнена в рамках госзадания Отделения физики диэлектриков и полупроводников ФТИ им. А.Ф. Иоффе РАН.

\section{Конфликт интересов}

Авторы заявляют, что у них нет конфликта интересов.

\section{Список литературы}

[1] G. Gautier, L. Ventura, R. Jérisian, S. Kouassi, C. Leborgne, B. Morillon, M. Roy. Appl. Phys. Lett., 88, 2501 (2006).

[2] C.C. Chung, M.G. Allen. J. Microelectromechan. Systems, 15, 1131 (2006).

[3] A.K. Samarao, F. Ayazi. IEEE Int. Electron Dev. Meet. (IEDM09), 789 (2009).

[4] W.G. Pfann. Zone-melting. 236 (John Wiley and Sons, NY.,1958)

[5] В.Н. Лозовский, Л.С. Лунин, В.П. Попов. Зонная перекристаллизация градиентом температуры полупроводниковых материалов 232 (Металлургия, М., 1987)

[6] H.E. Cline, T.R. Anthony. J. Appl. Phys., 47 (6), 2332 (1976).

[7] Э.Ю. Бучин, Ю.И. Денисенко, В.И. Рудаков. Письма в ЖТФ, 28 (24), 75 (2002). [E.Y. Buchin, Y.I. Denisenko, V.I. Rudakov. Tech. Phys. Lett., 28 (12), 1058 (2002).]

[8] S.I. Garmashov, V.Yu. Gershanov. J. Cryst. Gr., 311 (2), 413 (2009).

[9] В.Н. Лозовский, В.П. Попов, Б.М. Середин. ВАНТ Сер. Физ. радиац. возд. на радиоэлектрон. аппарат. 3, 57 (2015).

[10] А.А. Ломов, Л.С. Лунин, Б.М. Середин, Ю.М. Чесноков. ФТП, 51 (3), 297 (2017).

[11] Б.В. Молчанов, В.И. Рудаков. ПТЭ. 2, 155 (1996).

[12] Benjamin Morillon. Etude de la thermomigration de l'aluminium dans le silicium pour la réalisation industrielle de murs d'isolation dans les composants de puissance bidirectionnels. Micro et nanotechnologies/Microélectronique. Thesis. INSA de Toulouse, Français.

https://tel.archives-ouvertes.fr/tel-00010945. (2002). 
[13] А.С. Полухин. Компоненты и технологии, 11, 97 (2008).

[14] С.Ю. Князев, В.Н. Лозовский, В.С. Лозовский, Б.М. Середин. Письма в ЖТФ, 42 (10), 49 (2016). [S.Y. Knyazev, V.N. Lozovskii, V.S. Lozovskii, B.M. Seredin. Tech. Phys. Lett. 42 (10), 1045 (2016).]

[15] В.Н. Лозовский, Л.С. Лунин, Б.М. Середин. Электрон. техн. Сер. 2, Полупр. приборы, $2-3$ (236), 103 (2015).

[16] В.Н. Лозовский, Б.М. Середин, А.С. Полухин, А.И. Солодовник. Электрон. техн. Сер. 2, Полупр. приборы, 5 (239), 65 (2015).

[17] T. Yoshikawa, K. Morita. J. Elect. Chem. Soc., 150 (8), G465-G468 (2003).

[18] B.M. Seredin, V.V. Kuznetsov, A.A. Lomov, A.N. Zaichenko, S.Y. Martyushov. J. Phys.: Conf. Ser. 1400 (4), 044012 (2019).

[19] B. Girault, F. Chevrier, A. Joullie, G. Bougnot. J. Cryst. Gr. 37, 169 (1977).

[20] L. Murray, A.J. McAlister. J. Phase Equilibria, 1, 74 (1984).

[21] H.E. Cline, T.R. Anthony. J. Appl. Phys., 48 (6), 2196 (1977).

[22] D.K. Bowen, B.K. Tanner. High resolution X-ray diffractometry and topography. 252 (Tailor and Francis, London, 1998.)

[23] В.Н. Лозовский, А.А. Ломов, Б.М. Середин, С.Г. Симакин, А.Н. Заиченко, М.Б. Середина. Электрон. техн. Сер. 2, Полупр. приборы. 2 (245), 29 (2017).

[24] Э.Ю. Бучин, Ю.И. Денисенко, С.Г. Симакин. Письма в ЖТФ, 30 (5), 70 (2004).

[25] A. Lomov, A.Yu. Belov, B. Seredin, A. Tatarintsev, S. Simakin. Proceed. Intern. Conf. „Micro- and Nanoelectronics“ 2018” 139 (Moscow-Zvenigorod, Russia, 2018)

[26] L. Pauling. The Nature of the Chemical Bond, (3rd ed., Cornell UniversityPress, Ithaca, 1960)

[27] А.А. Ломов, Б.М. Середин, С.Ю. Мартюшов, А.Н. Заиченко, С.Г. Симакин, И.Л. Шульпина. Письма в ЖТФ, 46 (6), 27 (2020).

[28] K.L. Kavanagh. Phys. Rev. B, 45 (7), 3323 (1992).

[29] S. Haridoss, F. Beniere, M. Gaunean, A. Rupert. J. Appl. Phys., 51, 5833 (1980). 